\title{
8
}
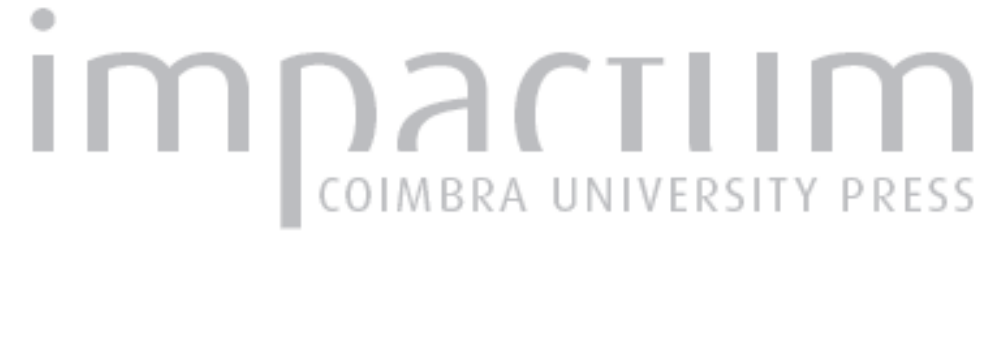

\section{De Lomé para Cotonou: as razões da Mudança}

\section{Autor(es): $\quad$ Cunha, Luís Pedro}

Publicado por: Faculdade de Direito da Universidade de Coimbra

URL persistente:

URI:http://hdl.handle.net/10316.2/24744

DOI:

http://dx.doi.org/10.14195/0870-4260_51_3

Accessed : $\quad$ 26-Apr-2023 14:37:26

A navegação consulta e descarregamento dos títulos inseridos nas Bibliotecas Digitais UC Digitalis, UC Pombalina e UC Impactum, pressupõem a aceitação plena e sem reservas dos Termos e Condições de Uso destas Bibliotecas Digitais, disponíveis em https://digitalis.uc.pt/pt-pt/termos.

Conforme exposto nos referidos Termos e Condições de Uso, o descarregamento de títulos de acesso restrito requer uma licença válida de autorização devendo o utilizador aceder ao(s) documento(s) a partir de um endereço de IP da instituição detentora da supramencionada licença.

Ao utilizador é apenas permitido o descarregamento para uso pessoal, pelo que o emprego do(s) título(s) descarregado(s) para outro fim, designadamente comercial, carece de autorização do respetivo autor ou editor da obra.

Na medida em que todas as obras da UC Digitalis se encontram protegidas pelo Código do Direito de Autor e Direitos Conexos e demais legislação aplicável, toda a cópia, parcial ou total, deste documento, nos casos em que é legalmente admitida, deverá conter ou fazer-se acompanhar por este aviso.

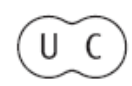




\section{UNIVERSIDADE DE COIMBRA \\ FACULDADE DE DIREITO}

BOLETIII DE CÊACCLS ECONÓNCACAS

VOLUME LI

$\begin{array}{llll}2 & 0 & 0 & 8\end{array}$

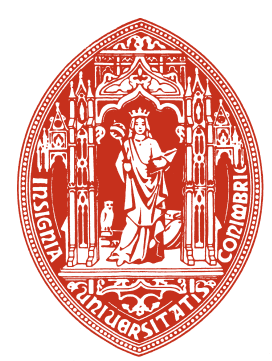

COIMBRA 


\section{DE LOMÉ PARA COTONOU: AS RAZÕES DA MUDANÇA}

\section{Introdução}

Procuraremos, neste trabalho, identificar os factores que explicam o fracasso do modelo das trocas comerciais que as convenções de Lomé adoptaram, percorrendo um caminho já, em parte, trilhado por convenções anteriores. Ao identificar esses factores deparar-nos-emos com parte substancial das razões que justificam a mudança para um novo modelo (ou modelos), já perspectivado no Acordo de Cotonou mas que só agora, em 2008, ganha indiscutível acuidade. Na verdade, neste último acordo previu-se a manutenção do regime das trocas comerciais da $4^{\mathrm{a}}$ Convenção de Lomé até fins de 2007. Só então se teria que dar corpo às várias hipóteses de regulação das trocas comerciais entre a União Europeia (UE) e os Estados ACP consagradas no Acordo de Cotonou.

Afirmámos que o fracasso do paradigma de regulação das trocas comerciais proposto pelas convenções de Lomé explicará, em larga medida, as mudanças previstas no Acordo de Cotonou. Não obstante, há também que considerar questões jurídicas, suscitadas por problemas de conformidade dos compromissos comunitários face aos países ACP com a regulação multilateral do comércio (em particular, com a regulação multilateral das relações comerciais preferenciais), 
e ainda a defesa de interesses próprios da UE. A estas matérias cabe também parte da responsabilidade da mudança de 'Lomé' para 'Cotonou' e a elas será dada a devida atenção.

\section{Do regime de associação previsto no Tratado de Roma à $4^{\mathrm{a}}$ Convenção de Lomé (revista) ${ }^{1}$}

A Comunidade Europeia (CE), desde a sua criação, procurou desenvolver relações privilegiadas com certos países e territórios africanos, alguns deles - em fins da década de 50 - ainda sob domínio europeu. Entre esses países e territórios e países europeus existiam, aliás, laços comerciais estreitos, assentes na concessão de preferências alfandegárias e em uma complementaridade comercial de tipo colonial. Vários foram os países fundadores da CE que pretenderam então instituir um regime particular de associação, que enquadrasse e estimulasse o desenvolvimento das relações económicas entre esses países e a Comunidade. A finalidade primeira desta associação seria a de promover o desenvolvimento económico e social dos países e territórios participantes.

Assim, está previsto no Tratado de Roma (TR), nos arts. $182 .^{\circ}$ ss. (numeração actual), "a associação dos países e territórios ultramarinos" (PTU) à CE. O sistema de associação previa a eliminação total dos impostos alfandegários aplicados nas trocas comerciais entre a CE e os PTU e

${ }^{1}$ Seguimos o que, em parte, já escrevemos em CunHa (1997: 185 ss.). Uma apreciação desenvolvida da matéria de que tratamos neste ponto - assim como uma explanação dos diversos aspectos do Acordo de Cotonou - pode ser encontrada em Paz Ferreira (2004: 361-423). Veja-se também Babarinde e Faber (2005) e Babarinde (2005). 
também entre estes últimos, ou seja, visava-se a (tendencial) instituição de uma (única) zona de comércio livre entre os participantes na associação. Esta eliminação seria realizada de forma gradual mas permitir-se-ia aos países e territórios associados manter posteriormente alguma protecção alfandegária, nomeadamente para efeitos reditícios ou de salvaguarda de indústrias nascentes. Também a concessão de ajuda directa para o desenvolvimento foi contemplada, tendo mesmo sido criado um instrumento financiador específico, o Fundo Europeu de Desenvolvimento (FED) ${ }^{2}$. Por último, consagravam-se os princípios da livre circulação de trabalhadores, entre os PTU e a CE, a concretizar posteriormente, e da aplicação não discriminativa do direito de estabelecimento.

Em 1963, é assinada a $1^{a}$ Convenção de Iaoundé, formalizando-se deste modo os laços entre a Comunidade e os dezoito estados da Organização Comum Africana e Malgache. Era intenção deste tratado estimular a industrialização dos países associados e a diversificação das suas economias. A $1^{a}$ Convenção de Iaoundé vigorou entre 1964 e 1969. Segue-se a $2^{a}$ Convenção de Iaoundé, sem novidades significativas, que vigora entre 1969 e 1975. Entre a associação prevista no TR e esta outra, objecto de tratados internacionais, encontramos algumas, no plano da regulação das trocas comerciais. Em primeiro lugar - já o dissemos - substitui-se um regime de associação estabelecido de forma marcadamente unilateral para um outro, de tipo convencional. Por outro lado, mantém-se o objectivo de se avançar na

2 Os vários $\mathrm{FED}$, que se foram sucedendo, garantiram, como afirma Stevens (2000: 225), uma estrutura de ajuda mais previsível e mais substancial em termos financeiros do que o que se verificava com os outros instrumentos comunitários de ajuda financeira a países em vias de desenvolvimento. Cfr. também CunHa (1997: 186; 181; 168). 
liberalização recíproca das trocas, mas agora através da pretendida formação de um conjunto de zonas de comércio livre, estabelecidas bilateralmente entre a Comunidade e cada um dos países em vias de desenvolvimento (PVD) associados. A prática revelou que a reciprocidade se afirmou verdadeiramente, na medida em que países associados concederam à CE preferências inversas ${ }^{3}$.

Com a adesão do Reino Unido à Comunidade, o alargamento da cobertura geográfica dos PVD com quem se pretendia cooperar estreitamente conduziu à assinatura da $1^{\mathrm{a}}$ Convenção de Lomé, em 1975 (já a Convenção de Arusha, assinada em 1968 e alterada em 1969, permitiu à Comunidade aplicar a alguns países ex-colónias britânicas o regime de associação definido nas Convenções de Iaoundé). No conjunto dos signatários associados predominam os países africanos, mas, pela primeira vez, integram este grupo de países Estados das Caraíbas e do Pacífico. Deste modo, a $1^{\mathrm{a}}$ Convenção de Lomé vinculou a CE, então formada por 9 Estados-membros, e os (então) 46 Estados ACP (18 países africanos e 28 Estados membros da Commonwealth).

À $1^{\text {a }}$ Convenção de Lomé sucederam-se duas outras, vigorando cada uma delas cerca de 5 anos. A 4 a Convenção de Lomé entrou em vigor em 1990, para vigorar dez anos. Um acordo de revisão dessa convenção foi assinado em 1995, contando a Comunidade, já à época, 15 Estados-membros, e integrando-se 70 Estados no grupo dos países ACP.

A $1^{\text {a }}$ Convenção de Lomé (e as seguintes) distingue-se das convenções de Iaoundé não apenas pelo número de países terceiros envolvidos mas também pelos objectivos que prossegue: estabelecer um novo modelo de relações entre os países desenvolvidos e os PVD (o designado modelo de Lomé)

${ }^{3}$ Cfr. Desta (2006: 1344, nota 6). 
caracterizado por: a) comércio preferencial não recíproco; b) estabilização de receitas das exportações; c) indexação de certos preços de exportação.

Com a previsão de um mecanismo de estabilização das receitas das exportações e a indexação de certos preços de exportação procura contrariar-se a tendência para a deterioração dos termos de troca dos PVD.

Instituem-se as melhores condições de entrada preferencial de mercadorias no mercado comunitário: quase todos os produtos originários dos países ACP são admitidos com preferências totais e sem quaisquer restrições quantitativas $^{4}$. É de salientar que, no que respeita a estes países, mesmo as exportações de têxteis para a Comunidade, tradicionalmente produtos muito sensíveis para esta, se vieram a revelar praticamente não contingentadas. Note-se que a concessão de tratamento pautal preferencial deixou de se subordinar à existência de reciprocidade ${ }^{5}$, contrariamente ao previsto nas convenções de Iaoundé ou no regime unilateral do TR supra mencionado. Neste ponto, a CE aquiesceu a uma pretensão de alguns Estados africanos. No plano jurídico, esta concessão de preferências alfandegárias de sentido único revelou-se controversa, face às disposições comerciais multilaterais. Exigia-se, no entanto, ausência de discriminação negativa (um tratamento pautal não menos favorável do que o da "nação-mais-favorecida" (NMF)) e previa-se uma cláusula de salvaguarda que podia ser invocada se, por via da cooperação comercial estabelecida, resultassem perturbações graves num sector da actividade económica da Comunidade ou de um ou mais Estados-membros ou o comprometimento da sua estabilidade financeira externa, ou ainda se surgissem dificuldades que ameaçassem deteriorar um sector

\footnotetext{
${ }^{4}$ Cfr. o n. ${ }^{\circ} 1$ dos arts. $168 .^{\circ}$ e $169 .^{\circ}$ da $4^{a}$ Convenção.

${ }^{5}$ Sublinhando este ponto, por exemplo, Ramos Díaz (2007: 123).
} 
de actividade da Comunidade ou de uma das suas regiões ${ }^{6}$. Note-se que esta cláusula de salvaguarda se apresentava menos restritiva do que aquela que acompanhava a concessão das preferências do Sistema de Preferências Generalizadas $(\mathrm{SPG})^{7}$ ou dos acordos celebrados com os países do Magrebe e do Machereque ${ }^{8}$.

A produtos abrangidos pela política agrícola comum determinou-se a aplicação de um regime de trocas particular. Este compatibilizava os interesses proteccionistas da política agrícola comum com o acesso preferencial ao mercado europeu de produtos agrícolas dos países ACP. Assegurou-se um tratamento pautal sistematicamente favorável mas este podia, no entanto, consubstanciar-se na previsão de preferências meramente parciais (e ser acompanhado de contingentes pautais e/ou limites temporais ou mesmo restrições quantitativas) ${ }^{9}$.

O comércio de determinados produtos (açúcar, arroz, carne, bananas, rum) veio a ser regulamentado por (sucessivos) protocolos específicos. Nesse âmbito, os ditos produtos vieram a contar com condições de acesso ao mercado comunitário especialmente favoráveis (preferências totais ou parciais, em regra de aplicação circunscrita a contingentes pautais, possivelmente crescentes), por vezes a preços garantidos, indexados a valores fixados no âmbito da política agrícola comum e situados, geralmente, bem acima dos preços

${ }^{6}$ Cfr. os arts. $174 .^{\circ}$ e $177 .{ }^{\circ}$ da $4^{\text {a }}$ Convenção. O conceito de tratamento da NMF referido não se aplica às relações económicas estabelecidas entre os Estados ACP ou entre um ou mais Estados ACP e outros PVD.

${ }^{7}$ Esta, por seu turno, tornou-se mais restritiva, quando se instituiu o 2. ${ }^{\circ}$ SPG. Cfr., a este propósito, Stevens et al. (1999: 35).

${ }^{8}$ Com esta indicação e outros desenvolvimentos, McQueEn (1998: 424; 427).

${ }^{9}$ Cfr. o n. ${ }^{\circ} 2$ dos arts. $168 .^{\circ}$ e $169 .^{\circ}$ da $4^{a}$ Convenção. 
mundiais (o caso do açúcar ${ }^{10}$ e da carne). Tal significou, para os produtores ACP, uma importante fonte de rendimentos, embora alguns destes produtos também fossem produzidos na CE.

O sistema de cooperação a favor dos países ACP, contemplando os domínios da cooperação comercial e da cooperação no âmbito de produtos específicos, abarcava igualmente a cooperação financeira e técnica, outras áreas de actuação, as quais, aliás, se foram alargando de convenção para convenção ${ }^{11}$, e ainda a dimensão política. Pode então afirmar-se que o sistema de Lomé veio a representar o sistema de cooperação para o desenvolvimento mais elaborado, seguro e global de todos os existentes à escala mundial ${ }^{12}$.

${ }^{10}$ V., a este propósito, Casanova DOMÈnech (2007).

${ }^{11}$ Cfr. Cunha (1997: 193).

12 Cfr. Casanova Domènech (2006: 947). No mesmo sentido, Paz Ferreira (2004: 389). Num plano distinto, Stevens (2000: 223), ao estabelecer, até certo ponto, um paralelo entre o sistema de cooperação de Lomé e o Espaço Económico Europeu. O autor lembra que, ao analisar-se as relações entre a Comunidade Europeia e os PVD, se sublinhava tradicionalmente a importância das convenções de Lomé. Lomé não só representava o mais generoso e abrangente regime de trocas comerciais preferenciais com o Terceiro Mundo como também se revelava um ambicioso instrumento comunitário de cooperação para o desenvolvimento, sem rival naquilo que caracterizava a política comunitária com os restantes PVD. Para Stevens, o sistema de Lomé só concorreria, mas num outro plano, com os acordos celebrados com os países da EFTA, na década de 70, e com a criação do Espaço Económico Europeu, nos anos 90. A nosso ver, deve, não obstante, registar-se que as finalidades da $4^{\mathrm{a}}$ Convenção de Lomé e do Tratado do Espaço Económico Europeu não se confundem, assim como não coincidem os tipos de integração pretendida entre as partes (num caso, temos fundamentalmente liberalização comercial de sentido único; no outro, avança-se e em extensos domínios - até à integração profunda). 


\section{O relacionamento comercial com os países ACP na estrutura das relações preferenciais desenvol- vidas pela CE. A "pirâmide" de preferências ou de privilégios}

Enquadraremos agora o relacionamento da Comunidade com os países ACP, ao tempo da vigência da $4^{a}$ Convenção de Lomé, na estrutura das relações comerciais preferenciais então desenvolvidas pela CE. Procuraremos assim situar, à época, este relacionamento na chamada "pirâmide" de privilégios ${ }^{13}$ ou de preferências comunitária para os PVD (e também, a partir de 1988, para os países com economias “em transição") ${ }^{14}$.

Começaremos, no entanto, por referir aqueles Estados que de todo não se integravam (ou não se integram) na referida "pirâmide" de privilégios: os EUA, o Japão, a Austrália, a Nova Zelândia e o Canadá15. Para estes, os impostos alfandegários previstos na pauta aduaneira comunitária, aplicados com base na cláusula da NMF, mantinham-se, em termos de tributação ordinária, como o grande instrumento regulador das trocas comerciais (a que acresciam outros instrumentos de defesa comercial, previstos em

${ }^{13}$ Uma designação que remonta a Mishalani et al. (1981).

14 Esqueceremos, num primeiro momento, os acordos com os países da EFTA, dos anos 70, e a criação do Espaço Económico Europeu, já na década de 90. Estes são acordos que habitualmente os autores não integram na pirâmide de privilégios comunitária, considerando-se que se estava, em regra, perante tratados celebrados com países desenvolvidos. Já Kreinin e Plummer (2007: 2) adoptam posição distinta, ao colocarem na pirâmide de preferências aqueles países que com a CE celebraram o Tratado do Porto e se mantêm como países associados (Islândia, Noruega, Liechtenstein) e ainda a Suíça.

${ }^{15}$ No entanto, na década de 90 cerca de $60 \%$ do comércio da CE extra-regional era realizado com estes países. Cfr. WTO (1995). 
acordos comerciais multilaterais). Estas economias não beneficiavam, nem beneficiam, de quaisquer preferências alfandegárias, podendo apenas arrogar-se o direito de não serem sujeitas a discriminação negativa (à margem ou ao arrepio das normas do GATT e da OMC).

Entrando na "pirâmide privilégios", pela base, deparávamo-nos então com os países latino-americanos e (alguns) asiáticos (v.g. Índia, Paquistão, Sri Lanka, Bangladesh). De entre os factores que comprovam que, para a $\mathrm{CE}$, as relações com estes países se situavam na periferia do seu relacionamento comercial preferencial ${ }^{16}$, destacamos dois.

Por um lado, estas economias eram, na década de 90 (e continuam a ser, no geral), beneficiárias do SPG. Este é um sistema aplicado unilateralmente pela CE, caracterizado por modestas preferências alfandegárias, as quais, quando incidiam sobre produtos de interesse para os PVD, eram, em regra, fortemente limitadas nos seus efeitos por limites quantitativos (contingentes pautais ou limites máximos pautais) ou outros. Para mais, contemplavam sobretudo produtos industriais, só acessoriamente incidindo sobre produtos agrícolas ${ }^{17}$ (pensando aliás neste últimos produtos, há também que recordar os efeitos perniciosos da política agrícola comunitária sobre as exportações dos países latinoamericanos, tanto para a Europa como para o resto do mundo).

Por outro lado, a CE celebrou tradicionalmente com estes países meros acordos comerciais e de cooperação. Tendencialmente, estes são acordos globalmente não preferenciais, embora possam conter a garantia da concessão mútua do tratamento da NMF e a obrigação de não se introduzirem

${ }^{16}$ Cfr. Cunha (1997: 164 ss.).

${ }^{17}$ Para uma análise desenvolvida do primeiro SPG (1971-1994) e uma referência ao segundo, veja-se CunHA (1995). 
novas barreiras comerciais entre a CE e os países terceiros envolvidos. Em sentido oposto, estes países acabaram por admitir vincular-se a diversos acordos de "autolimitação" de exportações de produtos sensíveis, os quais, embora sectorialmente, limitavam as suas exportações para o mercado comunitário, mesmo em condições não preferenciais.

No troço intermédio da "pirâmide" de preferências era usual colocar os países do Norte de África, do Magrebe (Argélia, Marrocos, Tunísia) e do Machereque (Egipto, Jordânia, Síria e Líbano). Com estes países a CE celebrou, na década de 70, verdadeiros acordos de associação, os quais, para além de estabelecerem a concessão de tratamento preferencial, lançaram as bases para a cooperação económica, financeira e técnica.

Note-se que a opção pela celebração de uma "série" de acordos de associação bilaterais significou a rejeição, para o Mediterrâneo, da orientação "global" plasmada no modelo das convenções de Iaounde e Lomé.

Nos acordos com os países do Magrebe e com os países do Machereque pretendia-se a reciprocidade, mas como objectivo a concretizar em prazo indefinido. $\mathrm{Na}$ verdade, estes países comprometeram-se apenas a não conceder às importações de origem comunitária um tratamento pautal inferior ao da NMF.

Por seu turno, as vantagens oferecidas pela $\mathrm{CE}$ às importações de países mediterrânicos revelaram-se claramente inferiores àquelas que beneficiavam os países $\mathrm{ACP}$ e não foram determinadas de forma completamente homogénea.

Em regra, a Comunidade comprometeu-se a admitir no seu mercado a generalidade dos produtos industriais destes países com isenção de tributação alfandegária (bem como de restrições quantitativas e de quaisquer outras taxas ou medidas de efeito equivalente). No entanto, a aplicação desta regra acabou por comportar excepções várias. Nestes casos, o comércio preferencial ficava sujeito à aplicação de limites 
máximos pautais. Por sua vez, o comércio de têxteis e de vestuário subordinou-se a convénios específicos, obviamente com efeitos limitativos das exportações destes países para a Comunidade.

A importação de produtos agrícolas estava, em termos gerais, sujeita a um regime caracterizado pela dualidade. Para produtos não abrangidos pela política agrícola comum, era garantido um acesso praticamente irrestrito ao mercado europeu, com concessão de preferência total (em casos raros, a concessão de tratamento pautal preferencial podia ser acompanhada de limites máximos). Para os produtos abrangidos pela política agrícola comum concediam-se preferências parciais, com reduções alfandegárias mínimas de 20\%, ou mesmo preferências totais. Mas, no que respeita a estes produtos, a concessão de tratamento alfandegário favorável podia ser acompanhada, conforme os casos, pela imposição de preços mínimos de importação, correspondentes a preços de referência fixados na Comunidade, pela aplicação de contingentes pautais ou ainda pela circunscrição do tratamento preferencial a certos limites temporais.

No topo da "pirâmide" (no lugar cimeiro da hierarquia das relações comerciais preferenciais) integravam-se, tradicionalmente, os países ACP. Já observámos que - pensando apenas no domínio estrito das trocas comerciais preferenciais - estes eram os países que contavam com as melhores condições de entrada no mercado comunitário (em regra preferências totais e sem quaisquer restrições quantitativas), sem que lhes fosse exigida reciprocidade; era apenas garantido aos produtores comunitários um tratamento não menos favorável do que o tratamento da NMF. Para mais, os países ACP beneficiavam, em termos gerais, de um quadro muito alargado de cooperação financeira e técnica. Contavam também com um sistema (STABEX) que visava garantir a estabilização das receitas das exportações de alguns produtos 
de base e de um outro (SYSMIN), pensado - em particular - para a promoção da produção de minérios.

$\mathrm{Na}$ década de 90 - aquela em que estamos a pensar e que antecede a vigência do Acordo de Cotonou - é ainda de realçar o caso de grande parte dos países da Europa Central e Oriental. Em relação a estas economias, há que registar um movimento ascensional, no que respeita à sua posição na escala hierárquica das relações comerciais e económicas da CE, o qual, aliás, ultimará com a adesão destes Estados à UE. De início, simples acordos comerciais e de cooperação regularam as relações económicas com alguns dos países do Leste, a partir de 1988 e numa $1^{\text {a }}$ fase de normalização das relações entre a $\mathrm{CE}$ e esses países; foram também acordos comerciais e de cooperação aqueles que estruturaram o quadro das relações com as repúblicas do Báltico (Estónia, Letónia e Lituânia), concluídos em 1992 e que vigoraram, na íntegra, até 1994.

Mais tarde, foram celebrados com estes países os chamados acordos europeus de associação, substancialmente equivalentes nas suas linhas gerais: cada um deles obedecia ao objectivo da criação de uma zona de comércio livre com a CE e, por conseguinte, todos eles previam a reciprocidade, ou seja, a concessão de preferências alfandegárias recíprocas; mas de forma assimétrica, ou seja, o desmantelamento alfandegário da CE iniciava-se mais cedo e a um ritmo mais rápido. Previa-se também a instituição, a prazo, da livre circulação de pessoas, capitais e serviços e a liberdade de estabelecimento. Podemos admitir que estes acordos se vieram a constituir num patamar para a futura adesão destes Estados associados à UE (foram aliás, a seu tempo, acrescidos pelas parcerias para a adesão). Não obstante, no momento da sua celebração e entrada em vigor, eles eram apenas, indiscutivelmente, acordos (de associação) que colocavam as economias do centro e do leste europeu no topo da "pirâmide" de privilégios comunitária, em detrimento dos países ACP. 
Note-se, porém, que a criação de um (maior) espaço de integração regional (quaisquer que viessem a ser os seus moldes efectivos) na Europa sempre terá sido motivação para os acordos europeus de associação, enquanto que as convenções de Lomé (e, antes destas, o regime de associação unilateralmente previsto no TR, as convenções de Iaoundé e a Convenção de Arusha) se explicam primordialmente pela tentativa de, oferecendo-se vantagens alfandegárias às importações de mercadorias produzidas nos países ACP, se procurar - por via da expansão das exportações desses países - promover o seu crescimento económico.

Regressando aos acordos europeus de associação, sublinhe-se que estes, originariamente, não obrigavam os países associados a tornar seu o acquis communautaire, na íntegra ou tendencialmente na íntegra (esquecemos desenvolvimentos posteriores). Nesta medida, distinguiam-se bem do Tratado do Porto, que abordaremos de seguida. Mas iam indiscutivelmente muito longe para os padrões de relacionamento então vigentes entre a CE e PVD "do Sul”18 Os países associados obrigavam-se a convergir com a UE em várias dimensões, v.g. no âmbito do direito da propriedade intelectual e da concorrência ${ }^{19}$. Recorde-se também - e de novo - a liberalização dos investimentos e da prestação de serviços.

O Tratado do Espaço Económico Europeu, assinado no Porto em 1992, consagra os princípios da livre circulação de mercadorias, de pessoas e de capitais, a liberdade de estabelecimento e a livre prestação de serviços entre a CE e

${ }^{18}$ Cfr. Winters (2000: 198).

${ }^{19}$ Entre outros, a "aproximação" das legislações abrangia os seguintes domínios: legislação aduaneira, direito das sociedades, direito bancário, contabilidade e fiscalidade das empresas, propriedade intelectual, serviços financeiros, regras de concorrência, protecção dos consumidores, fiscalidade indirecta, regras e normas técnicas, transportes e ambiente. 
os países da EFTA, mas não prevê a instituição de uma união aduaneira e de uma política comercial comum; da mesma forma, avançou-se pouco em termos de integração do sector agrícola e das pescas. Importa, no entanto, sublinhar que a criação do Espaço Económico Europeu (EEE) implicou que cerca de $80 \%$ da legislação comunitária respeitante ao mercado interno único se viesse a aplicar a todos os países membros, v.g. nos domínios do direito da concorrência, do direito do estabelecimento e da livre circulação de trabalhadores e de capitais $^{20}$. A intenção terá sido a de garantir aos países associados os benefícios económicos da instituição do mercado interno único, sem lhes exigir, è época, os laços políticos que resultariam da sua integração na Comunidade. O acordo do EEE entrou em vigor em Janeiro de 1994 e - com o grande esforço de harmonização legislativa contido - acabou por facilitar significativamente a adesão à UE da Áustria, Suécia e Finlândia (1995). Actualmente, são membros do EEE, para além da CE, a Islândia, a Noruega e o Liechtenstein.

Mesmo que no âmbito do EEE se assistisse, indiscutivelmente, à associação à CE de países europeus desenvolvidos, de economia de mercado, com a intenção de fortalecer a integração regional na Europa, há neste acordo traços que, embora por demais carregados, anunciam o que se passará em futuros acordos com o resto do mundo (a liberalização comercial em novos domínios e o desenvolvimento de processos de integração profunda, relacionada com a convergência internacional de legislações).

${ }^{20}$ Para mais desenvolvimentos v. Frisch e Meyer (1992). 


\section{As razões da mudança}

\subsection{O fracasso do regime das trocas comerciais de Lomé}

Neste ponto, procuraremos identificar alguns dos factores que explicam a mudança de "Lomé" para "Cotonou". Iniciaremos as nossas considerações pela análise das causas do fracasso do regime de trocas comerciais de Lomé (causas estas que se revelem exógenas, face às condições internas das economias dos países ACP, e que, por conseguinte, se relacionem privilegiadamente com as condições em que se realiza o comércio internacional preferencial garantido aos países ACP).

O fracasso do regime de trocas comerciais de Lomé reflecte-se, embora de forma não indiscutível ${ }^{21}$, nos seguintes números. Em 1976, as importações da CE de produtos originários de países ACP representavam $6,7 \%$ do comércio extra-comunitário, enquanto que, em 2003, significavam apenas 3\%. Por outro lado, 65\% destas importações continuam concentradas em produtos primários ${ }^{22}$.

Pode então assinalar-se a marginalização dos países ACP, na sua qualidade de parceiros comerciais da CE. A este propósito, refira-se ainda os seguintes dados: em 1976, considerando cinco grupos de países (ACP, latino-americanos, "novos países industrializados" da Ásia Oriental/

${ }^{21}$ McQueEn (1998: 425) questiona a irrelevância das preferências de Lomé. Para o efeito, recorda a falta de um "anti-mundo", ou seja, da possibilidade de, contrafactualmente, saber o que teria acontecido na ausência de Lomé. Lembra também que o aumento substancial das importações de PVD não produtores de petróleo (e não ACP) se deveu, em larga medida, ao aumento substancial das exportações de produtos manufacturados, por parte de um pequeno grupo de países do Leste e do Sudeste Asiáticos.

22 Cfr. Casanova Domènech (2006: 951-952, nota 22). A autora refere dados do Eurostat. 
ASEAN, mediterrânicos e do Sul da Ásia), os países ACP eram a segunda fonte de importações comunitárias originárias de PVD, ultrapassados apenas pelos países mediterrânicos. Em 1996, os países ACP tinham sido arredados para o penúltimo lugar, superando apenas as economias do Sul da Ásia. Para mais, eram os únicos que, entre 1976 e 1996, apresentavam uma tendência decrescente (calculadas as suas exportações para a UE como percentagem das importações da UE extra-comunitárias, os valores passaram de 6,3\% em 1976 para 3,8\% em 1996). Encontramos um padrão similar, quando analisamos as exportações comunitárias para os países ACP. Estas significavam, em 1976, 6,8\% de todas as exportações comunitárias (comércio extra-regional) e, em 1996, apenas 3\%23.

A teoria económica ensina que as preferências alfandegárias estimularão as exportações dos países beneficiários se produzirem efeitos de criação e de desvio de comércio. Os primeiros dar-se-ão com a substituição de produção

${ }^{23}$ Cfr. Stevens (2000: 228-229). O autor chega a levantar a possibilidade de ter existido uma relação inversa entre preferências comerciais e perfomance comercial, para logo a seguir a rebater, lembrando que outros PVD, os países mediterrânicos, contavam também com tratamento pautal preferencial relevante e que tal não obstou a um (pequeno) aumento da sua importância como fonte de importações comunitárias (7,6\%, em 1976; 8,3\%, em 1996)... Quando muito - conclui STEVENS -, preferências comerciais, ou melhor, regimes de trocas comerciais privilegiados como aqueles que se estipulavam em protocolos para produtos específicos (açúcar, bananas) poderiam funcionar como elementos dissuasores de uma diversificação das exportações. Em sentido convergente, Casanova Domènech (2006: 947). Para a autora, as preferências alfandegárias não foram capazes, em geral, de fomentar a expansão e a diversificação das exportações dos países ACP nem lograram, em última instância, uma maior integração destes países na economia mundial. 
comunitária por produção dos países recipientes das preferências. Os segundos com a substituição de exportações de países terceiros discriminados, no mercado comunitário, por produção dos mesmos países beneficiários de tratamento pautal favorável, dirigida ao mesmo mercado. A este propósito apontaremos, em primeiro lugar, factores inibidores da produção de efeitos de criação de comércio, seguindo-se outros que explicarão que não se tenha podido contar com significativos efeitos de desvio de comércio

\subsubsection{Factores inibidores de criação de comércio}

Neste domínio, mencionaremos aspectos da composição das exportações dos países ACP e das políticas agrícola e comercial comunitárias que já abordámos, em texto precedente ${ }^{24}$.

Aí afirmámos que, sendo certo que o regime de Lomé é habitualmente tido como muito vantajoso, já que praticamente todas as exportações dos países ACP para a Comunidade estão isentas de tributação alfandegária, há que notar que cerca de $3 / 4$ dessas exportações são compostas por produtos de base, muitas vezes concorrenciais não de produção comunitária mas antes de produção de países terceiros ${ }^{25}{ }^{26}$.

Por outro lado, o desenvolvimento da política agrícola comum revelou-se um obstáculo à livre entrada no mercado comunitário dos produtos agrícolas com origem em países

${ }^{24}$ Cfr. Cunha (1997: 190-191).

${ }^{25}$ Lembrem-se os casos do cacau e das bananas, produtos em que os exportadores ACP gozam tradicionalmente de tratamento preferencial, em detrimento dos produtores latino-americanos.

${ }^{26}$ No entanto e de acordo com algumas estimativas (apontadas por Grilli, 1993: 31), cerca de 70\% das exportações de produtos com origem em países ACP que efectivamente concorriam com produção comunitária entravam na CE com isenção de tributação alfandegária. 
ACP concorrentes de produção comunitária, pese embora as concessões feitas para estes países, nestes produtos ${ }^{27} 28$.

Também no que respeita à produção industrial, a CE tem, em certa medida, protegido os seus produtores da concorrência dos países ACP, desencorajando o desenvolvimento da capacidade de exportação destes países em certos produtos sensíveis, como o vestuário e os têxteis de algodão. Para o efeito, socorreu-se de mecanismos de vigilância da evolução das importações de certos produtos com origem nestes países e mesmo da aplicação de limites máximos pautais, eventualmente repartidos pelos Estados-membros.

Outros obstáculos à expansão das exportações dos países ACP para a Comunidade encontrar-se-ão na definição das regras de origem, consideradas como sendo restritivas ${ }^{29}$ ou até distorçoras ${ }^{30}$, e na previsão de uma cláusula de salvaguarda (v. supra), que, pelo simples facto de estar prevista na Convenção de Lomé, condiciona negativamente o aumento do investimento, da produção e das exportações de produtos a que a CE é tradicionalmente sensível.

${ }^{27}$ Neste sentido, entre outros, CASANOva DOMÈnECH (2006: 951).

28 Não obstante, o facto de a importação de certos produtos, abrangidos por protocolos específicos, já mencionados, se ter vindo a fazer aos preços praticados no âmbito desta política comunitária, em regra muito acima dos preços mundiais, beneficiou estes países. Naturalmente, os preços garantidos só serão vantajosos enquanto, no âmbito da política agrícola comum, continuarem a ser fixados a níveis artificialmente elevados. Há, actualmente, factores que podem vir a deprimir estes preços (pressões orçamentais comunitárias, alargamento da UE para Leste, liberalização multilateral no domínio da produção agrícola) Cfr. Stevens et al. (1999: 14; 37) ou Stevens (2000: 235).

${ }^{29}$ V.g. McQueEN (1998: 428).

${ }^{30}$ Delaplace (2001: 615). 


\subsubsection{Factores inibidores de desvio de comércio}

4.1.2.1. A evolução da "pirâmide de preferências" comunitária

Tradicionalmente, a CE concede tratamento pautal preferencial à generalidade dos produtos industriais e a alguns produtos primários com origem em PVD (pense-se, nomeadamente, nos acordos mediterrânicos ou no SPG). O regime de Lomé é, em regra, mais vantajoso do que aqueles com que outros países em desenvolvimento podem contar, mas a concorrência entre diversos regimes preferenciais produz necessariamente efeitos de erosão das preferências de que beneficiam os países ACP, i.é, reduz-lhes as margens de preferências face a PVD terceiros que exportam para a Comunidade produtos concorrentes.

O facto a que acabámos de aludir - a participação dos países de Lomé numa "pirâmide de privilégios" comunitária, em lugar cimeiro mas, apesar de tudo, em concorrência com outras economias - ganhou novos contornos nos últimos anos e em detrimento destes países. Recorde-se, a este propósito, a aproximação comunitária aos países da Europa Central e Oriental, que já abordámos. Refira-se também os novos acordos euromediterrânicos de associação $(v \cdot g$. com a Tunísia ou Marrocos). Nestes acordos, não só encontramos definida uma liberalização comercial recíproca, para produtos industriais, capaz de dar corpo à criação de zonas de comércio livre entre a $\mathrm{CE}$ e os Estados terceiros associados $^{31}$, como se assiste mesmo, para determinadas matérias, a um esforço de convergência de legislações, algo que não mais significa do que uma aproximação da legislação dos países associados à legislação comunitária ${ }^{32}$. No acordo com

31 A prazo, prevê-se a instituição de uma única zona de comércio livre euromediterrânica.

32 Sobre esta matéria - a do desenvolvimento de processos de integração profunda entre países ou/e espaços de integração regional, 
Marrocos, por exemplo, está prevista a adopção de regras comunitárias da concorrência, assim como de standards e procedimentos de certificação de produtos industriais e agro-alimentares, algo que é relevante no âmbito do combate às barreiras não pautais ao acesso ao mercado europeu ${ }^{33} 34$.

Em matéria de (novos) acordos de associação, que permitam redefinir a relação de concorrência entre o relacionamento preferencial dos países ACP com a CE e os termos da aproximação comunitária a outros países ou regiões do mundo, há também que referir recentes acordos de associação com países latino-americanos (os acordos com o México e com o Chile já estão em vigor; decorrem, com o mesmo desiderato, negociações com o Mercosul). Estes prevêem a liberalização comercial progressiva para bens e serviços, ultimando-se na criação de zonas de comércio livre ${ }^{35}$.

Para uma correcta explicitação da actual hierarquização das relações preferenciais comunitárias), há ainda que aludir à Iniciativa “Tudo Menos Armas” (TMA). Esta Iniciativa da

em particular quando estes apresentam diferentes níveis de desenvolvimento -, pode ver-se CunHA (2008: 509 ss).

33 Por outro lado, os mesmos acordos não se revelam particularmente ambiciosos em outros domínios. O acesso ao mercado europeu de produtos agrícolas não é substancialmente liberalizado e não se assumem efectivos compromissos no que respeita a serviços, investimento e estabelecimento. Cfr., para o acordo com a Tunísia, Winters (2000: 199) e, para o acordo com Marrocos, Stevens et al. (1999: 59 ss).

34 A Turquia, que com a CE instituiu uma união aduaneira, também desenvolveu esforços de convergência de legislações, em matérias como direito da concorrência e da propriedade intelectual e ainda standards. Cfr. Winters (2000: 198).

35 Para mais desenvolvimentos, cfr. Palomares Amat (2008: 54-56). 
UE, instituída em Março de $2001^{36}$, garante a todos os produtos (exceptuando armas e munições) com origem nos menos desenvolvidos dos PVD, os chamados "países menos avançados” (PMA), uma entrada no mercado europeu com isenção de tributação alfandegária e sem significativos contingentes quantitativos. Em apenas três casos não se deu, logo de início, uma liberalização imediata e completa (bananas, arroz, açúcar). Para estes produtos, estipulou-se um processo de diminuição gradual dos níveis de tributação aplicáveis (até 2006, para as bananas, e até 2009, para os outros produtos) e, simultaneamente, instituíram-se contingentes alfandegários para o arroz e o acúcar, com preferência total e com valores crescentes, ano após ano.

É importante notar que a maioria dos produtos originários destes países já beneficiavam de isenção de tributação alfandegária, ao abrigo do SPG ou do Acordo de Cotonou (41 PMA são países ACP). De qualquer forma, ao abrigo desta Iniciativa, 919 produtos (agrícolas ou alimentares processados), antes excluídos de tratamento pautal preferencial (e/ou objecto de contingentação quantitativa), vieram a contar com este tipo de tratamento e com a eliminação das quotas; só em 44 casos se adiou uma completa liberalização comercial $^{37}$.

A Iniciativa TMA procurou fazer face à comprovação de que as preferências alfandegárias proporcionadas pela $\mathrm{CE}$ a PVD, v.g. no que respeita ao SPG, não tinham, nas três décadas em que haviam vigorado, proporcionado resultados efectivos, de expansão das exportações, para estes países, ou, no mínimo, não o teriam feito uniformemente. Para trás

${ }^{36}$ Cfr. Reg. (CE) n. ${ }^{\circ} 416 / 2001$, JOCE, n. ${ }^{\circ} 60$ da série L, de 1 de Março de 2001, e Reg. (CE) n. ${ }^{\circ}$ 2501/2001, JOCE, n. ${ }^{\circ} 346$ da série L, de 31 de Dezembro de 2001.

${ }^{37}$ Cfr. Brenton (2003: 625). 
teriam sobretudo ficado, de entre os PVD, aqueles com menores níveis de rendimento (PMA). Esta "Iniciativa" veio, por conseguinte, a afirmar-se como um instrumento de discriminação positiva para estes países ${ }^{38}$, com a intenção declarada de lhes facilitar uma maior integração na economia mundial ${ }^{39}$.

Uma importante característica desta Iniciativa está no facto da sua regulação se inserir no SPG comunitário (mais precisamente, no quadro do "Super-SPG PMA"). Por outras palavras, o acesso ao mercado europeu garantido pela Iniciativa TMA faz-se de acordo com regras inscritas na regulamentação do SPG. Por conseguinte, não se exige reciprocidade.

Em 2003, PMA que se integrassem no grupo dos países ACP podiam escolher o regime das trocas comerciais previsto no Acordo de Cotonou ou optar pelo regime comercial da Iniciativa TMA. Para os PMA que não se contassem no seio do grupo dos países ACP, a Iniciativa TMA revelava-se como uma garantia de acesso livre ao mercado europeu, nos termos já expostos, com uma capacidade de

${ }^{38}$ Os EUA responsabilizaram-se por iniciativa similar, ao abrigo do African Growth and Opportunity Act. Para uma crítica deste sistema, veja-se MatтоO et al., 2002.

${ }^{39}$ De início, foi pouco sucedida. 99\% dos produtos habitualmente exportados pelos países beneficiários (PMA) já gozavam de livre importação (por outras palavras, o imposto da NMF já era igual a zero), pelo lado europeu, sendo que, no que respeita a outros produtos, de interesse para estes países (arroz, açúcar, bananas), decidiu-se, como vimos, adiar a finalização do processo de liberalização. É naturalmente nestes produtos e no respectivo processo de liberalização comercial, com incidência na eliminação de impostos e de contingentes, que radica o previsível impacto destas preferências. Para mais, também nestes casos regras de origem restritivas foram provavelmente responsáveis por uma subutilização das preferências disponíveis. Cfr. BRENTON (2003: 623-624). 
rivalizar com o regime das trocas comerciais de Lomé claramente superior à do tradicional SPG.

BRENTON (2003: 626-627) refere, com dados estatísticos, que, entre 2000 e 2001, os países ACP exportaram a vasta maioria dos produtos liberalizados sob os auspícios da Iniciativa TMA. Outros países tiveram, nesta matéria, responsabilidade marginal, embora, para alguns deles (v.g. o Bangladesh), a UNCTAD tivesse identificado potencial de exportação. Não obstante, o mesmo autor faz notar que as exportações dos países ACP supra mencionadas se fizeram ao abrigo do Acordo de Cotonou. Já outros PMA, não ACP, utilizaram efectivamente as preferências dessa Iniciativa, limitados embora pelos seus volumes de exportações. $\mathrm{O}$ autor destaca um factor explicativo para o comportamento dos países ACP, que nos interessa realçar porque torna visível o impacto que esta Iniciativa teve na inserção dos países ACP na "pirâmide de privilégios": as regras de cúmulo de origens variam substancialmente do sistema de preferências SPG/TMA para o Acordo de Cotonou, sendo que aos países ACP estão vedados os cúmulos diagonais de origens previstos no sistema SPG. Ao abrigo destas cumulações diagonais de origens, o cúmulo pode fazer-se em âmbito de integração regional, nos casos da Associação das Nações do Sudeste Asiático (ASEAN), do Mercado Comum da América Central, da Comunidade Andina e da Associação da Ásia do Sul para a Cooperação Regional (SAARC). Tal não obsta a que, em matéria de origem cumulativa, o Acordo de Cotonou preveja, no seguimento das convenções de Lomé, o chamado "cúmulo" integral, no qual participam todas as economias ACP e até alguns países vizinhos (para além da Comunidade). Este será, em termos gerais, mais generoso do que simples cúmulos diagonais ${ }^{40}$. Não obstante, em casos parti-

${ }^{40}$ No mesmo sentido, McQueEn (1998: 424). 
culares, no que se refere a laços comerciais com os países da ASEAN e da SAARC, reduzem-se as possibilidades dos países ACP (PMA) adquirirem inputs dessas economias asiáticas sem "perderem" a origem ${ }^{41}$.

${ }^{41} \mathrm{Na}$ sequência, BRENTON alerta que os países ACP que vierem a transitar do regime de Cotonou para o regime TMA podem vir a ser prejudicados por regras de cúmulo de origens mais restritivas, nomeadamente em termos de (futura) diversificação das exportações. Neste particular, a Iniciativa TMA não é substituto do Acordo de Cotonou. Por fim, o mesmo autor sublinha que, também nas negociações para os futuros acordos de parceria económica (APE), as regras de origem devem ser tratadas pelos países ACP envolvidos como uma questão fundamental.

Também para Rocha (2003), as regras de origem da Iniciativa TMA são menos generosas do que aquelas que se aplicam ao abrigo do Acordo de Cotonou e serão, provavelmente, ainda mais restritivas do que aquelas que se aplicarão no seio dos APE. As regras TMA não permitem a cumulação diagonal entre países ACP. Isto provavelmente explicou, em larga medida, porque é que em 2001, o primeiro ano da aplicação das preferências desta Iniciativa TMA, os países ACP utilizaram-nas em menos de 5\% das suas exportações para a UE elegíveis para o sistema. Estes dados provam que, havendo opção, há, na perspectiva dos países ACP, vantagem em exportar ao abrigo das regras de Cotonou. A prazo, a opção desaparecerá - restará a Iniciativa TMA -, a não ser que estes países negoceiem APE, com regras de origem mais simples e menos proteccionistas. Esta é a opção defendida por RoCHA, que, aliás, chama ainda a atenção para o facto de a Iniciativa TMA ser tomada unilateralmente pela CE, podendo pois ser eliminada sem negociações ou notificação.

Por seu turno, ARTs (2003: 108) pergunta-se qual será o incentivo dos países ACP "menos avançados" para se associarem à CE através da celebração de APE (que exigem reciprocidade), tendo os mesmos países garantida a continuação de acesso preferencial não recíproco ao mercado europeu, ao abrigo da Iniciativa TMA. Esquece-se o autor da importância e da sensibilidade da questão das regras de origem (embora a mencione). O mesmo lapso (a nosso ver) é cometido por LebULlenger (2001-2002: 83). Da mesma forma, PEREZ (2006), presumindo que a UE proporcionará aos países ACP alternativas de acesso preferencial ao seu mercado, face à celebração dos APE, fundadas no SPG e na Iniciativa TMA, que não 


\section{Uma (outra) diferença entre as preferências da Iniciativa TMA e o SPG - também ele um sistema de preferências}

signifiquem deterioração das condições garantidas pelo regime de trocas comerciais de Lomé - e supondo também que outros benefícios garantidos pelas convenções de Lomé e pelo Acordo de Cotonou, de natureza não alfandegária, se mantêm, independentemente da celebração dos APE, pronuncia-se contra a participação dos países ACP nos ditos acordos.

Não discutimos que o primeiro pressuposto de que Perez parte os países ACP, através da Iniciativa TMA e do SPG, manterão o acesso com que vêm contando ao mercado europeu - ajuda a tornar óbvia a vantagem, para estes países, da não celebração de APE. Estes, ao obrigarem à reciprocidade, mesmo que a prazo, e ao incidirem sobre países que têm mantido níveis de protecção alfandegária ordinária (da NMF) face à produção da UE (o primeiro dos exportadores para estes mercados), arriscam-se a provocar desequilíbrios comerciais entre estas economias e a economia europeia, em prejuízo das primeiras, a gerarem quebras no comércio ("regional") entre os países ACP e a provocarem uma diminuição na produção industrial destes países (tudo isto com depauperação da receita alfandegária, custos de ajustamento e deterioração nos termos de troca). Nestas circunstâncias, é relativamente fácil defender, na óptica dos países ACP, as alternativas que temos vindo a apontar, desde que os pressupostos de que partimos se revelem realistas. É neste ponto que supomos poder criticar-se PEREZ, por se revelar excessivamente optimista.

Ainda para Brenton (2003: 643), já não são questões de acesso ao mercado aquelas que comprometem a perfomance produtiva e de exportação dos países ACP "menos avançados". Antes é fundamental a diversificação das exportações destes países, mesmo que associada a preferências alfandegárias. E - para o efeito - será vital levar a cabo uma flexibilização das regras de origem. Também CASAnOva Domènech (2006: 955; 961) aponta para a necessidade de reexaminar e simplificar as regras de origem, incluídas as referentes a cúmulos de origens, que se aplicam às exportações de PMA ACP para a UE. Estas serão as regras de origem que se aplicam no âmbito do SPG europeu, também elas frequentemente criticadas (Rocha (2003: 15) é um dos autores que mais recentemente o faz. Para o efeito lembra que estudos actuais provam que PVD à partida beneficiários do SPG exportam para a UE em condições não preferenciais, por falta de capacidade para cumprirem as regras de origem). 
autónomas - reside no facto de as primeiras - dirigidas unicamente a PMA - recorde-se -, terem sido, à partida, garantidas por um período indeterminado e não estarem sujeitas a avaliação periódica. Este é um ponto fundamental, na medida em que se garantem condições de expansão de exportações e de acesso ao mercado europeu a produtores de países beneficiários em condições de certeza e estabilidade superiores àquelas que tradicionalmente caracterizam o SPG (prevê-se, não obstante, uma cláusula de salvaguarda, que permite a suspensão temporária das preferências em casos de acréscimo "maciço" e inesperado de importações de produtos abrangidos pelas preferências, com possíveis efeitos opostos àqueles que referimos precedentemente).

\subsubsection{A progressiva liberalização do comércio mundial}

Por seu turno, a progressiva liberalização do comércio mundial, verificada com o Uruguay Round, causou pelo menos um duplo prejuízo aos países ACP, na sua qualidade de parceiros comerciais preferenciais da CE, favorecidos por efeitos de "desvio de comércio".

Por um lado, esta liberalização, traduzida num conjunto de reduções alfandegárias multilaterais (não discriminativas), provocou erosão nas preferências alfandegárias. Estas terão, para os países recipientes, um valor que depende directamente do nível do imposto da NMF. Naturalmente, todas as preferências alfandegárias perderam "vitalidade" com este processo de desmobilização pautal multilateral e não apenas aquelas que respeitam a estes países. Nas palavras de STEVENS (2000: 225), as "fundações" de todo o edifício das relações comerciais preferenciais da CE, construído ao longo de décadas, enfraqueceu com a liberalização comércio mundial.

Por outro lado, recorde-se que um dos aspectos mais importantes do regime das trocas comerciais de Lomé residia 
no facto de os produtores dos países ACP estarem excluídos dos acordos de autolimitação das exportações, assumidos ao abrigo de sucessivos acordos multifibras Ora, com o Uruguay Round, determinou-se a eliminação progressiva das restrições quantitativas aplicadas à importação de têxteis e vestuário no decurso de um período de tempo que se entendeu, de início, prolongar até 2005 e dividir em três etapas.

\subsection{A questão da compatibilidade do regime das trocas comerciais de Lomé com as regras multilaterais do comércio internacional}

Referiremos agora, com brevidade, a influência que conflitos comerciais dirimidos multilateralmente tiveram na comprovação de que o regime de trocas comerciais UE-ACP não é susceptível de, com segurança jurídica e estabilidade, se revelar compatível com as regras do GATT e da OMC.

A CE foi, por várias vezes, acusada, no seio do GATT e agora da OMC, de ter estabelecido um regime de importação preferencial de bananas que violava as regras dessa organização internacional. O regime em causa, com a instituição do mercado interno único, foi sujeito a alterações. O novo sistema garantia as tradicionais quotas de mercado dos produtores latino-americanos, mas praticamente impedia estes de aumentarem a sua penetração no mercado comunitário, salvaguardando-se os produtores de bananas de África e das Caraíbas e impedindo-se que estes fossem prejudicados pelos primeiros ${ }^{42}$.

Sendo este um regime previsto nas convenções de Lomé, desenhou-se então um conflito entre o respeito

${ }^{42}$ Cfr. Stevens (2000: 233-234). 
comunitário por essas convenções e por disposições comerciais multilaterais, em particular as do GATT. Países latino-americanos apresentaram queixas no GATT e, mais tarde, os EUA procederam da mesma forma, no seio da OMC. Tendo a CE justificado o regime de importação preferencial de bananas invocando a Convenção de Lomé, colocou-se a questão da compatibilidade desta com o GATT. Este problema de compatibilidade foi (temporariamente) ultrapassado quando a Comunidade logrou obter uma derrogação, para a $4^{\text {a }}$ Convenção de Lomé, até $2000^{43}$ (posteriormente, a CE obteve uma nova derrogação, em 2001, para prolongar até fins de 2007 o regime das trocas comerciais de Lomé, já na vigência do Acordo de Cotonou). Entretanto, continuaram as disputas em torno da importação comunitária preferencial de bananas $^{44}$ (e de outros produtos ${ }^{45}$ ). Tal funcionou como um catalisador ${ }^{46}$ para se criar a convicção de que o ou os instrumentos de política comercial e de cooperação para o desenvolvimento que viessem a suceder à $4^{\mathrm{a}}$ Convenção de Lomé teriam que revelar uma maior consistência com as regras da OMC, que apenas em casos contados admite especificamente que membros desta organização concedam tratamento pautal preferencial (art. 24. ${ }^{\circ}$ do GATT; art. 5. ${ }^{\circ}$ do GATS; “cláusula de habilitação”).

O facto de, nas convenções de Lomé, se garantir, a favor dos países ACP, a concessão de preferências alfande-

\footnotetext{
${ }^{43}$ V., sobre esta primeira derrogação, MCMAHON (1999: 608 ss.).

${ }^{44}$ V., a este propósito, mais recentemente, READ (2005).

${ }^{45}$ Para o caso do acúcar, ver Hoekman e Howse (2008).

46 Em sentido convergente, Stevens et al. (1999: 13), quando afirmam: “...a chance set of events (the WTO banana dispute) has had a disproportionate impact by shattering the shell of a relationship that already had been fundamentally weakened by decades of gradual
} underlying change." 
gárias não recíprocas, em violação, por conseguinte, da cláusula da NMF estipulada no art. 1. ${ }^{\circ}$ do GATT, levanta a questão da compatibilidade desta prática com o direito da OMC. Sendo possível derrogar-se a obrigação supra mencionada recorrendo ao art. 24. ${ }^{\circ}$ do mesmo GATT ou à chamada "cláusula de habilitação" (parte de um acordo do Tokyo Round intitulado "Tratamento diferenciado e mais favorável, reciprocidade e participação mais completa dos PVD”), deve, no primeiro caso, estar-se perante a constituição, mesmo que a prazo e em condições de desmobilização pautal assimétrica, de um espaço de integração regional (união aduaneira ou zona de comércio livre), ou seja, exige-se reciprocidade (algo que o regime de Lomé não prevê); no segundo caso, o tratamento pautal preferencial que países desenvolvidos destinem aos seus parceiros menos desenvolvidos deve contemplar todas as economias em vias de desenvolvimento e não apenas parte delas, ou seja, impede-se a selectividade na definição dos recipientes de tratamento pautal favorável (nos termos do mesmo acordo, só o grupo dos chamados "PMA" poderá assumir-se como um universo distinto de economias beneficiárias de preferências alfandegárias particularmente favoráveis; ora parte dos Estados ACP não se integram neste subgrupo de PVD mais atrasados no seu processo de desenvolvimento económico). Já a possibilidade geral de concessão de derrogações, antes prevista no art. $25 .^{\circ}$, n. 5 do GATT, permitia a uma parte no GATT e, actualmente, ao abrigo do n. 3 do art. 9. ${ }^{\circ}$ do acordo que institui a $\mathrm{OMC}$, permite a um membro desta organização internacional eximir-se do cumprimento de uma obrigação multilateral, desde que este, para o efeito, obtenha uma deliberação favorável (com exigência de maioria qualificada). Seja como for, mesmo quando a derrogação é concedida, esta é-o em termos temporalmente balizados, ou seja, em condições de precariedade, e, para mais, não impede que 
um membro que se considere afectado nos seus interesses possa reagir, na defesa desses interesses ${ }^{47}$. Resta referir a Parte IV do GATT. Esta foi invocada pela CE, em articulação com o art. 24. ${ }^{\circ}$ do GATT, para justificar a concessão das preferências alfandegárias de sentido único de que temos vindo a tratar, no âmbito da $1^{a}$ Convenção de Lomé. Não obstante, nem a Parte IV permite tratamentos discriminativos, embora permita que os países desenvolvidos, na base da aplicação da cláusula da NMF, avancem concessões que interessam especialmente a economias menos desenvolvidas (sem esperar reciprocidade) ${ }^{48}$, nem a sua articulação com o art. $24{ }^{\circ}$ poderia proporcionar uma mudança da finalidade desta última norma. De instrumento de assimilação (e controlo) do fenómeno da integração regional, no seio do multilateralismo, o art. 24..$^{\circ}$ assumir-se-ia então (e não apenas tacitamente, como chegou a verificar-se) como um instrumento de estímulo ao desenvolvimento económico. Por outro lado, não se admitiria que a articulação entre a Parte IV do GATT e o art. 24. ${ }^{\circ}$ permitisse que o recurso a esta última norma proporcionasse o não cumprimento das obrigações do GATT (nomeadamente daquela que se inscreve no art. $1 .^{\circ}$ do mesmo acordo) em termos mais permissivos do que aqueles que o próprio art. $24 .^{\circ}$ estipula ${ }^{49}$.

47 Neste sentido, Lebullenger (2001-2001: 79) e Casanova Domènech (2006: 954, nota 28). Recorde-se, por exemplo, o "caso" Bananas II.

${ }^{48}$ Cfr. o art. $36 .^{\circ}$ do GATT, n. ${ }^{\circ} 8$.

${ }^{49}$ A propósito dos entendimentos a que, sobre esta matéria, foram chegando grupos de trabalho constituídos (ainda) no seio do GATT, veja-se Huber (2000: 428-430) e Lebullenger (2001-2002: 77 ss.). 


\section{Observações finais}

Tem-se revelado na UE a tendência para o progressivo afastamento de um modelo de trocas comerciais de sabor algo colonialista, caracterizado pela importação de matérias-primas com origem em PVD e pela exportação de produtos industriais para os mesmos países. Assiste-se agora, pelo menos no que respeita às trocas comunitários com parte dos PVD (em regra, asiáticos), a fluxos, nos dois sentido, de produtos industriais e serviços. Os países ACP não estão bem representados neste novo padrão de trocas comerciais ${ }^{50}$.

Por outro lado, também a progressiva liberalização das trocas comerciais e outras causas de diluição (do valor) das preferências levam a que os PVD tenham que se afastar de um modelo de trocas comerciais de dependência (preferenciais), que revela uma eficácia decrescente, para apostarem num modelo de maior diversificação, tanto no que respeita às bases das suas exportações, como no que toca aos mercados para onde exportam.

Em terceiro lugar, o escrutínio da OMC representa igualmente um desafio à manutenção de regimes de trocas comerciais preferenciais de sentido único e contratualizados (entre a UE e Estados terceiros associados).

No que se refere a este último ponto, não temos dúvidas que a inserção de países ACP na lista de beneficiários do SPG ou da Iniciativa TMA não revela melindre, no plano jurídico ${ }^{51}$. A "cláusula de habilitação", já referida,

${ }^{50}$ Cfr. Stevens (2000: 224).

${ }^{51}$ Nem em outros planos. A este propósito, citamos Mathis (2000: 145): “... GSP can always be criticized for its preferential nature. However, it is certainly 'multilateral' in the sense that it is already an endorsed GATT mechanism for granting preferences to less-developed countries without reference to regions, permits for graduation in respect 
torna lícita a concessão autónoma de preferências alfandegárias a estes países, por parte da UE, sem exigências de reciprocidade. Não obstante, registe-se que, se qualquer uma destas possibilidades permite tornar lícita a concessão de tratamento pautal discriminatório, nenhuma delas garante a eficácia das preferências alfandegárias concedidas. Continuarão a verificar-se efeitos de erosão de preferências, pelas razões mencionadas

A celebração de APE entre a UE e alguns países ACP tem, também ela, capacidade para, se se basear no cumprimento estrito dos requisitos do art. 24. ${ }^{\circ}$ do GATT (em particular), não suscitar questões de natureza jurídica, de compatibilidade do regime comercial que venha a estabelecer-se entre os signatários desses acordos com as disposições multilaterais pertinentes. Faltará, no entanto, conhecer as exactas características desses acordos para ajuizar sobre a sua consistência, face às regras do GATT e da OMC. Pela nossa parte, temos a convicção que nada garante desde já que os APE não possam vir a revelar-se de licitude duvidosa, face a essas regras.

Para mais, mesmo que questões de natureza jurídica não venham a emergir, como resultado da celebração desses acordos, temos dúvidas sobre a capacidade dos APE - independentemente da sua exacta configuração - virem a corresponder, fundamentalmente, aos interesses dos países ACP (nomeadamente uma maior integração na economia mundial e a diversificação das suas exportações).

of development levels, and does not require reverse preferences on behalf of the recipients." Também STEvens (2005) reconhece a um SPG (renovado) a capacidade para, a par de outros instrumentos de política comercial ou de cooperação para o desenvolvimento, assegurar a países ACP a manutenção de um relacionamento comercial próximo com a UE. 
Já para a UE é inegavelmente vantajosa a celebração destes acordos. Fundamentalmente, por dois motivos (para além de um terceiro, o de diminuírem os riscos de violação das normas da OMC, pelas razões já apontadas. De qualquer forma, esta é uma vantagem que a UE partilhará com Estados terceiros associados).

Exigem-se preferências inversas, mesmo que no decurso de processos de desmobilização pautal assimétricos. Ora, a celebração pela CE de acordos de comércio livre (acordos euromediterrânicos de associação, APE), tem, entre outras motivações, o objectivo de melhorar balanças comerciais bilaterais da UE, na medida em que, por um lado, tendo os países associados níveis mais elevados de protecção alfandegária, neles far-se-ão sentir mais fortemente os efeitos do desmantelamento pautal, e porque, por outro, sempre se logra limitar o acesso ao mercado europeu de produtos de maior sensibilidade (nomeadamente produtos agrícolas) ${ }^{53}$. Para mais, quando se assiste à celebração (ou ainda à negociação) de uma série de acordos de comércio livre com países mais distantes, que nada têm de parceiros comerciais "naturais" (México, Chile, Mercosul), tem-se, na perspectiva europeia, o objectivo adicional de assegurar acesso preferencial a mercados externos afastados, até para fazer face a iniciativas de integração regional que aí se localizam (no âmbito do chamado "novo regionalismo"). Procurar-se-á assim atenuar ou reverter a discriminação alfandegária de

52 Cfr. McQueen (1998: 421-422). No sentido de reproduzir nos APE modelos já ensaiados, Feuer (2002: 290). Para o autor, no quadro da parceria comercial criada pelo Acordo de Cotonou, o essencial talvez resida na intenção das partes de concluírem novos acordos comerciais visando a liberalização das trocas, do tipo daqueles que foram concluídos com a Tunísia, Marrocos ou o Líbano, no quadro do processo de Barcelona. 
que eventualmente se possa vir a sofrer ${ }^{53}$. Por último, proporciona-se a oportunidade para levar a cabo, em âmbito regional, ensaios de liberalização sobre domínios que não os das mercadorias (v.g. o dos serviços ${ }^{54}$ ) e ainda processos de integração profunda ${ }^{55}$.

${ }^{53}$ Cfr. Winters (2000: 195). A defesa dos mercados (externos) assumir-se-á então como motivação para a concessão comunitária de preferências alfandegárias, a par daquelas que são as duas finalidades tradicionais dos acordos comerciais preferenciais: uma (maior) integração regional na Europa e o estímulo ao desenvolvimento económicos de PVD.

${ }^{54}$ Cfr. o art. $41 .^{\circ}$ do Acordo de Cotonou e, em especial, o seu n. ${ }^{\circ}$ 4. Para mais, autores como Stevens e Kennan (2001: 4) defendem que a fixação de regras preferenciais para novos tipos de comércio, nomeadamente o dos serviços, deve fazer parte do objecto das negociações entre os países ACP e a UE, no quadro da tentativa de um aprofundamento das regras multilaterais já em vigor.

55 Cfr. os arts. $45 .^{\circ}$ a $51 .^{\circ}$ do mesmo Acordo, sobre política da concorrência, protecção dos direitos de propriedade intelectual, normalização e certificação, medidas sanitárias e fitosanitárias, comércio e ambiente, comércio e normas do trabalho, política dos consumidores e protecção da saúde dos consumidores. 


\section{BIBLIOGRAFIA CITADA}

Arts, Karin

2003 - "ACP-EU Relations in a New Era: The Cotonou Agreement", Common Market Law Review, vol. 40, pp. 95-116

BABARINDE, Olufemi

2005 - "The Changing Environment of ACP-EU Relations", in

Olufemi Babarinde e Gerrit Faber (eds.), The European Union and the Developing Countries - The Cotonou Agreement, Martinus Nijhoff Publishers, pp. 17-35

Babarinde, Olufemi; Faber, Gerrit

2005 - "From Lomé to Cotonou: ACP-EU Partnership in Transition",

in Olufemi Babarinde e Gerrit Faber (eds.), The European Union

and the Developing Countries - The Cotonou Agreement, Martinus

Nijhoff Publishers, pp. 1-15

Brenton, Paul

2003 - "Integrating the Least Developed Countries into the World

Trading System: The Current Impact of European Union

Preferences Under 'Everything But Arms"”, Journal of World Trade, vol. 37, n. ${ }^{\circ}$ 3, pp. 623-646

Casanova Domènech, M. ${ }^{a}$ Elisa

2006 - "Los Acuerdos de Asociación Económica UE-ACP: Un enfoque

pro-desarrollo", Revista de Derecho Comunitario Europeo, n. ${ }^{\circ} 25$, pp. 945-970

2007 - "El régimen del azúcar UE-ACP: Un instrumento de cooperación al desarrollo?", Cuadernos Europeus de Deusto, n. ${ }^{\circ} 36$, pp. 127-151

Cunha, Luís Pedro

1995 - O sistema comunitário de preferências generalizadas - efeitos e limites, separata do Boletim de Ciências Económicas da Faculdade de Direito da Universidade de Coimbra 1997 - Lições de relações económicas externas, Almedina

2008 - O sistema comercial multilateral e os espaços de integração regional, Coimbra Editora 
Delaplace, Dominique

2001 - "L’Union européenne et la conditionnalité de l'aide au développement", Revue trimestrielle de doit européen, vol. 37, n. ${ }^{\circ} 3$, pp. 609-626

Desta, Melaku Geboye

2006 - "EC-ACP Economic Partnership Agreements and WTO Compatibility: An Experiment in North-South Interregional Agreements?”, Common Market Law Review, vol. 43, n. ${ }^{\circ}$ 5, pp. 1343-1379

Ferreira, Eduardo Paz

2004 - Valores e Interesses - Desenvolvimento Económico e Política Comunitária de Cooperação, Livraria Almedina

FEUER, Guy

2002 - “Un nouveau paradigme pour les relations entre l'Union Européenne et les Etats ACP - L'Accord de Cotonou du 23 Juin 2000", Revue Générale de Droit International Public, n. ${ }^{\circ}$ 2, pp. 269-293

Frisch, Gert-Jürgen; Meyer, Catherine-Anne

1992 - "Le traité sur l'Espace Économique Européen: cadre juridique d'une «Europe du deuxième cercle»", Revue du Marché Commun et de l'Union Européenne, n. ${ }^{\circ} 360$, pp. 596-602.

Grilli, Enzo R.

1993 - The European Community and the Developing Countries, Cambridge University Press.

Hoekman, Bernard; Howse, Robert

2008 - "EC-Sugar", World Trade Review, vol. 7, pp. 149-178

HuBER, Jürgen

2000 - "The Past, Present and Future ACP-EC Trade Regime and the WTO”, European Journal of International Law, vol. 11, n. ${ }^{\circ}$ 2, pp. 427-438

Kreinin, Mordechai E.; Plummer, Michael G.

2007 - "Regional groupings, discrimination, and erosion of preferences: Effects of EU enlargement on the Mediterranean Basin”, The Journal of International Trade \& Economic Development, vol. 16, n. ${ }^{\circ} 2$, pp. 213-230 (na versão em linha que utilizámos, a numeração das páginas é de 1 a 27)

LEBULLENGER, Joël

2001-2002 - "Les dispositions commerciales de l'accord de partenariat $\mathrm{ACP} / \mathrm{CE}$ de Cotonou confrontées aux règles de l'OMC”, Revue des affaires européennes, n. $^{\circ} 1$, pp. 75-91 
Mathis, James H.

2000 - "The Community's External Regional Policy in the WTO" in

Pitou Van Dijck e Guerrit Faber (eds.), The External Economic

Dimension of the European Union, Kluwer Law, pp. 127-149

Mattoo, A.; Roy, D.; Subramanian, A.

2002 - "The Africa Growth and Opportunity Act and its Rules of

Origin: Generosity Undermined?", World Bank Policy Research

Working Paper 2908

McMahon, Joseph A.

1999 - "Negotiating in a Time of Turbulent Transition: The Future of

Lomé”, Common Market Law Review, vol. 36, pp. 599-624

McQueEn, Matthew

1998 - "Lomé Versus Free Trade Agreements: The Dilemna Facing the

ACP Countries", The World Economy, vol. 21, n. ${ }^{\circ}$ 4, pp. 421-443

Mishalani, P.; Robert, A.; Stevens, C.; Weston, A.

1981 - "The Pyramid of Privilege", in C. Stevens (ed.), EEC and the

Third World: A Survey 1, Hodder and Stoughton, cap. 4. ${ }^{\circ}$

Palomares Amat, Miquel

2008 - "Propuestas para un nuevo marco jurídico de las relaciones entre

la Unión Europea y América Latina”, Revista de Derecho Comu-

nitário Europeo, n. ${ }^{\circ} 29$, pp. 49-89

Perez, Romain

2006 - "Are the Economic Partnership Agreements a First-best

Optimum for the African Caribbean Pacific Countries?”, Journal of

World Trade, vol. 40, n. ${ }^{\circ}$ 6, pp. 999-1019

Ramos Díaz, Javier

2007 - "La Estrategia para el. Desarrollo Económico y Social (Lisboa,

2000) y las políticas de Cooperación (Cotonou, 2000): Preparán-

donos para afrontar la globalización en el siglo XXI?”, Cuadernos

Europeos de Deusto, n. ${ }^{\circ}$ 37, pp. 111-130

READ, Robert

2005 - "The 'Banana Split': the EU-US Banana Trade Dispute and the

Effects of EU Market Liberalisation", in Nicholas Perdikis e

Robert Read (eds.), The WTO and the Regulation of International

Trade - Recent Trade Disputes between the European Union and the

United States, E Elgar, pp. 109-134

Rocha, Manuel de la

2003 - "The Cotonou Agreement and Its Implications for the Regional

Trade Agenda in Eastern and Southern Africa", World Bank Policy

Research Working Paper 3090

Stevens, Christopher

BOLETIM DE CIÊNCIAS ECONÓMICAS LI (2008), pp. 25-62 
2000 - "The EU-ACP Relationship after Lomé”, in Pitou Van Dijck e Guerrit Faber (eds.), The External Economic Dimension of the European Union, Kluwer Law, pp. 223-243

2005 - "An Alternative Strategy for Free Trade Areas: The Generalized System of Preferences", in Olufemi Babarinde e Gerrit Faber (eds.), The European Union and the Developing Countries - The Cotonou Agreement, Martinus Nijhoff Publishers, pp. 111-125

Stevens, Christopher; Kennan, Jane

2001 - Post-Lomé WTO-Compatible Trading Arrangements, Commonwealth Secretariat

Stevens, Christopher; McQueen, Matthew; Kennan, Jane

1999 - After Lomé IV: A Strategy for ACP-EU Relations in 21t Century, Commonwealth Secretariat

WinTERs, L. Alan

2000 - "EU's Preferential Trade Agreements: Objectives and Outcomes", in Pitou Van Dijck e Guerrit Faber (eds.), The External Economic Dimension of the European Union, Kluwer Law, pp. 195-222

Wто (World Trade Organization)

1995 - Regionalism and the World Trading System, World Trade Organization

\author{
Luís Pedro Cunha \\ Professor Auxiliar \\ da Faculdade de Direito de Coimbra
}

BOLETIM DE CIÊNCIAS ECONÓMICAS LI (2008), pp. 25-62 